\title{
Relationships between Strong Ground Motion Peak Values and Seismic Loss during the 1999 Chi-Chi, Taiwan Earthquake
}

\author{
YIH-MIN WU $^{1 \star}$, NAI-CHI HSIAO ${ }^{1}$ and TA-LIANG TENG ${ }^{2}$ \\ ${ }^{1}$ Central Weather Bureau, 64 Kung-Yuan Road, Taipei 100, Taiwan ROC; ${ }^{2}$ Southern California \\ Earthquake Center, University of Southern California, Los Angeles, California, USA
}

(Received: 25 October 2002; in final form: 20 June 2003)

\begin{abstract}
A better real-time assessment of earthquake effects (i.e. seismic intensity estimation) is crucial for hazard mitigation. Especially during the aftermath of a disastrous event, significant reduction of loss can usually be realized through timely execution of emergency response measures. These effects include strong-ground shaking, ground failure, and their impact on man-made structures. The descriptive Modified Mercalli intensity scale, though still in common use in many poorly instrumented areas of the world, is out of date in areas of extensive strong-motion instrumentation. It is desirable to place the earthquake intensity scale on a more quantitative basis based on the actual recorded ground-motion shaking and carefully compiled damage records. In this paper, we investigated the relationships between earthquake loss, intensity and strong motion peak values, mainly based on the Chi-Chi earthquake. Both the strong-motion peak values and the earthquake loss are related. From the results, we found that peak ground acceleration (PGA) and peak acceleration response spectra at $1 \mathrm{~s}$ period $(1 \mathrm{~s} \mathrm{Sa})$ values are two parameters that give slightly higher correlation coefficients than other parameters for earthquake loss analysis. For intensity estimations, the peak ground velocity (PGV) values and $1 \mathrm{~s} \mathrm{Sa}$ values are better parameters in the high range and PGA is not stable for smaller earthquakes. Although PGV values give a slightly lower correlation coefficient and larger standard deviation in seismic loss analysis during the Chi-Chi earthquake, it nevertheless gives more reliable instrumental intensity over a broad magnitude range. $1 \mathrm{~s} \mathrm{Sa}$ is a good parameter for both seismic losses and intensity evaluation. We thus conclude that PGV and $1 \mathrm{~s} \mathrm{Sa}$ are relatively more stable in damage assessment and, at least in the high end, in intensity estimation. We shall incorporate these findings in our real-time earthquake rapid reporting and early warning systems.
\end{abstract}

Key words: seismic hazard mitigation, seismic damage assessment, peak ground motion, earthquake rapid reporting system.

\section{Introduction}

Real-time strong motion monitoring is becoming an important tool for seismic hazard mitigation (Kanamori et al., 1997; Teng et al., 1997; Wu et al., 1997). In Taiwan both an earthquake rapid reporting system and an earthquake early warning system have been developed by the Central Weather Bureau (CWB), and were placed in routine operation as early as 1995 (Teng et al., 1997; Wu et al., 1997,

\footnotetext{
^ Author for correspondence. E-mail:ym.wu@ socmail.cwb.gov.tw
} 
1998, 1999, 2000, 2001; Wu and Teng, 2002). These two systems are based on a telemetered strong-motion network, and their outputs enable real-time assessment of the damage and life loss as an earthquake is happening. This provides crucial information for earthquake disaster mitigation and rescue responses. The earthquake rapid reporting system of the CWB, named Taiwan Rapid Earthquake Information Release System (TREIRS), currently consists of 82 telemetered strong-motion stations distributed in the Taiwan area (Figure 1). TREIRS stations are complemented by another 650 free-field digital strong-motion stations installed under the Taiwan Strong-motion Instrumentation Program (TSMIP). These 650 stations are distributed throughout Taiwan, with especially dense installations in populous metropolitan areas. All TREIRS and TSMIP stations in Figure 1 are equipped with modern digital accelerographs, using force-balanced accelerometers (FBAs) as their sensing elements. These FBAs are broadband (nominally from DC to $50 \mathrm{~Hz}$ ), large dynamic range (from $10^{-7} \mathrm{~g}$ to $2 \mathrm{~g}$ ), and suitable for on-scale recording of the largest earthquake. Accelerographs used in the TREIRS network are equipped with digital output streams. The FBA digital data output streams (3-components) can be easily multiplexed with the velocity digital data stream (3-components) from the co-sited CWBSN Teledyne S-13 short-period velocity sensors to form a frequencymultiplexed signal for data telemetry. At the CWB recording headquarters, signal from this real-time telemetered signal will be de-multiplexed and 3-component strong-motion data from all TREIRS stations can be extracted. With the application of a set of time-domain recursive filters (Kanamori et al., 1999), we can derive, essentially in real-time, all kinds of ground motion signals such as acceleration, velocity, displacement, and response spectra, etc. Thus, the instrumental design of the TREIRS telemetered network and the built-in data processing software packages make it possible that many kinds of strong-motion signals can be simultaneously presented at the monitoring headquarters. Any such signal can be extracted for purposes such as seismic hazard evaluation and earthquake damage assessment. Based on the TREIRS strong-motion waveform and the actual records of damage and life loss during the 1999 Chi-Chi, Taiwan earthquake, a correlation analysis is performed in this study. We hope to find a set of most useful strong-motion parameters that will help refine the seismic hazard evaluation before a major event, and a method of earthquake damage assessment immediately after a disastrous earthquake.

\section{Damage Data Compilation from the 1999 Chi-Chi, Taiwan Earthquake}

The correlative parametric study described above requires an extensive strongmotion waveform and the associated damage data sets. The 1999 Chi-Chi, Taiwan earthquake was the largest onland earthquake to occur in Taiwan in the twentieth century. It occurred at a time when both strong-motion instrumentation programs in Taiwan (TSMIP and TREIRS) were completed and instruments were in place. This earthquake inflicted severe damage in central western Taiwan and caused ex- 


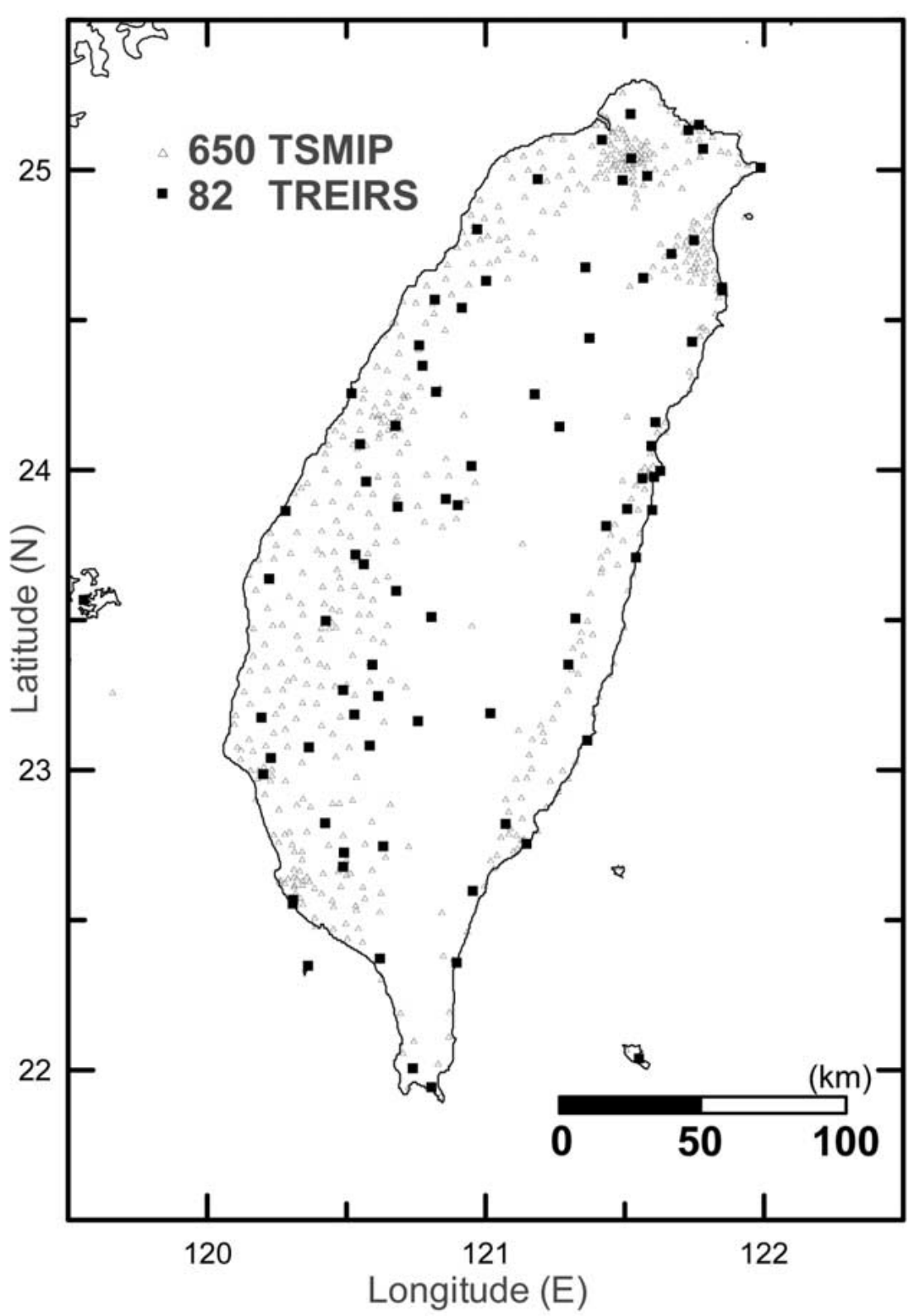

Figure 1. Map of Taiwan showing the distribution of the 650-station Taiwan Strong-Motion Instrumentation Program (TSMIP) network and the 82-station telemetered Taiwan Rapid Earthquake Information Release System (TREIRS). 
tensive building collapses, including many high-rise buildings, from the epicentral region to the Taipei basin some $150 \mathrm{~km}$ away. About 2500 people were killed as a consequence. However, out of the severe losses, excellent strong-motion data of this earthquake were collected, and extensive damage statistics were compiled by the National Office of Statistics (2000). These two data sets provide an excellent opportunity to derive quantitative relationships between strong ground motion parameters and earthquake losses. A preliminary study between peak ground motion and earthquake losses of the Chi-Chi earthquake was reported by Tsai et al. (2001). They pointed out that ground accelerations correlated well with earthquake fatalities and building collapses. For examples, in towns experiencing more than 400 gals, ${ }^{\star}$ the fatality rates rapidly increased to 11 per 1,000 population and building collapse rates to $52 \%$, whereas for shaking less than 250 gals the fatalities rates were all below 0.018 per 1,000 and building collapse rates below $0.04 \%$. Tsai et al. (2001) also found that the numbers of totally and partially collapsed households were about equal. In our previous study (Wu et al., 2003), we also established empirical relationships between, respectively, the peak ground acceleration (PGA), the peak ground velocity (PGV) and seismic losses during the Chi-Chi earthquake. However, there are many other relevant strong-motion parameters (other than PGA and PGV) that may provide a closer correlation with seismic losses. These parameters are considered in this paper.

In this study, using the extensive Chi-Chi strong-motion data and seismic loss statistics, we carried out a regression analysis seeking quantitative relationships between strong ground motion peak values (including PGA, PGV, seismic-wave intensity, and acceleration and velocity response spectra at various periods, as well as the average response spectra etc.) and seismic losses. A reliable quantitative relationship will improve the ability of rapid damage assessment for seismic hazard mitigation purposes.

\section{Strong-Motion Data}

The TSMIP was successfully implemented by the CWB four years before the occurrence of the 1999 Chi-Chi earthquake. At the same time, the telemetered realtime strong-motion network (TREIRS) was also in full operation. With about 650 modern digital accelerographs installed at free-field sites (Figure 1), the TSMIP signals are digitized at 200 samples per second or higher and at 16-bit resolution. Most accelerographs have clipping recording ranges of $\pm 2 \mathrm{~g}$. The TSMIP records offer detailed description of ground shaking for, among other things, damage assessment. Over 30,000 digital strong-motion records have been obtained from the Chi-Chi earthquake and its aftershocks, causing a several fold increase in the total world holding of strong-motion data of important large events. For the mainshock, strong-motion records from 441 TSMIP stations were recovered (Lee et al., 2001). These mainshock strong-motion records were used to derive a set of eleven para-

\footnotetext{
$\star 1 \mathrm{gal}=1 \mathrm{~cm} / \mathrm{s}^{2}$.
} 
meters that formed the strong-motion input data for this regression analysis. Since all these eleven parameters (or their time signals) can be obtained simultaneously in a real-time seismic network operation, any parameter can be selected in real-time earthquake rapid reporting and earthquake early warning purposes if that parameter is particularly useful in certain aspects of strong shaking prediction and damage assessment. These eleven derived parameters are:

(a) Three peak acceleration response spectra, $\mathrm{Sa}$, at $0.3 \mathrm{~s}, 1 \mathrm{~s}$, and $3 \mathrm{~s}$ period.

(b) Three peak velocity response spectra, $\mathrm{Sv}$, at $0.3 \mathrm{~s}, 1 \mathrm{~s}$, and $3 \mathrm{~s}$ period.

(c) Two average response spectra of acceleration and velocity.

(d) Peak acceleration, PGA.

(e) Peak velocity, PGV.

(f) Peak seismic wave intensity, SWI, defined by Ouchi et al. (2001) as the product signal of acceleration and velocity which has the dimension of the strong-motion shaking power.

Because of the extensive TSMIP station coverage, we could calculate values of these strong ground motion parameters for essentially any field point. In particular, we calculated these values for the centers of individual townships in Taiwan, where the National Office of Statistics (2001) compiled all their building damage and life loss data (Figure 2). This allows a correlative analysis from which we sort out useful ground motion parameters in order to improve our ability to report in real-time the intensity prediction and damage assessment.

\section{Fatality and Building Collapse Data}

Two types of earthquake loss data (fatalities and totally collapsed households in individual townships) during the 1999 Chi-Chi earthquake were entered into the analysis. Although, partially collapsed household data were also collected by the Taiwan National Office of Statistics. However, according the results of Tsai et al. (2001), the numbers of totally and partially collapsed households were about equal. Thus, in this study we only use totally collapsed households data for the analysis. Figure 3 gives the building collapse rate in Central and northern Taiwan together with the PGA contours for the Chi-Chi event. An insert at bottom of Figure 3 shows the damage statistics in the Taipei metropolitan region some $150 \mathrm{~km}$ away form the epicenter. We used households instead of the number of the buildings as the basis of collapse structures. The reasons are:

(1) The data in terms of the number of the totally collapsed households was collected by the Taiwan National Office of Statistics.

(2) The number of the households is a better index than the number of buildings. For example, a high-rise building may contain several tens to hundreds of households, a low-rise building may contain one or two households.

Here, a "household" means an officially registered dwelling unit. On average, there are about 3.3 persons per household in Taiwan area. 


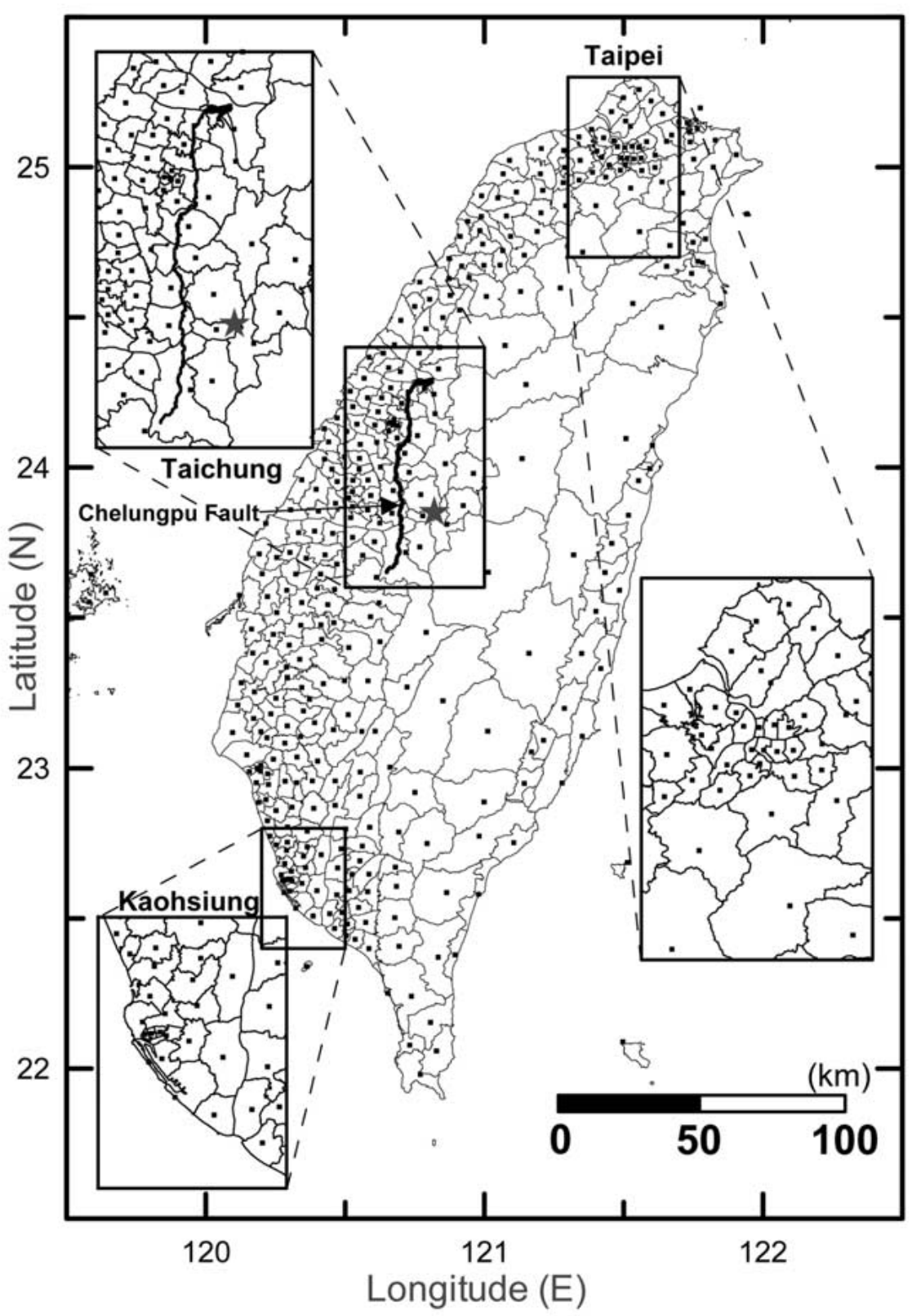

Figure 2. Distribution of townships in Taiwan, a solid square gives the geographic center of each township where earthquake damage and fatality data are compiled by National Office of Statistics (2001). 


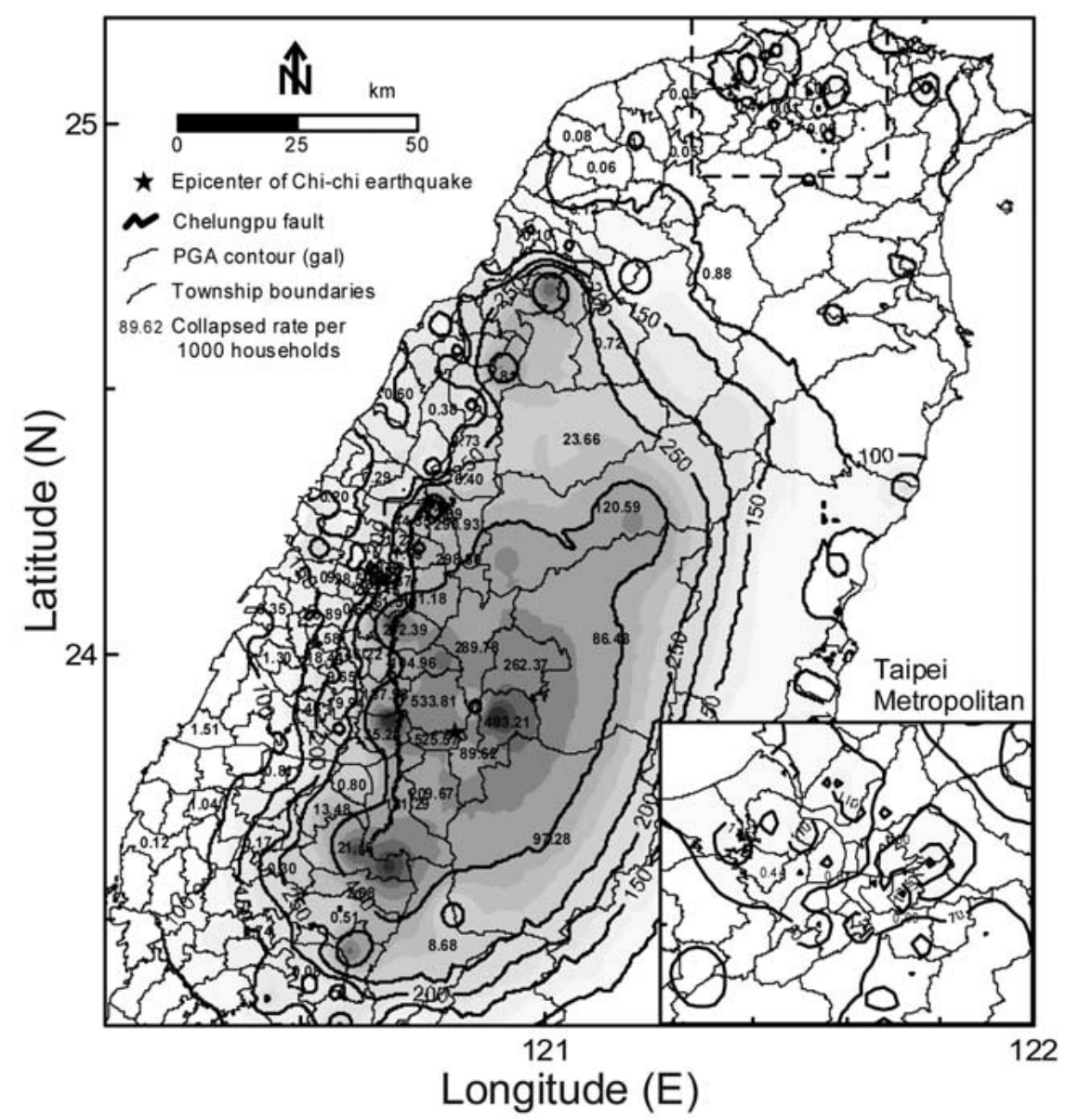

Figure 3. An enlarged map of central-northern Taiwan showing the Chi-Chi epicenter, the causal Chelungpu fault, PGA contours, township boundaries, and the household collapse rate figures.

\section{Results of Regression Analysis}

For regression analysis, we applied the Kriging method (Cressie, 1990) to calculate from a set of input with spatially irregular sample points (i.e. 441 TSMIP station records of the 1999 Chi-Chi earthquake) for strong ground motion parameter peak values at 365 township geometrical centers in Taiwan (Figure 2). Averaged damage rate in different strong ground motion parameter peak values range were determined for regression analysis. Generally, eleven to fourteen averaged damage rate readings were determined versus different strong ground motion parameters (Tables I and II). Logarithm of the averaged damage rate $(D)$ was found to be linearly related to the logarithms of the strong ground motion parameter peak values $(S)$ as follows: 
Table I. Regression analysis parameters between household collapse rate and strong motion peak values during the 1999 Chi-Chi earthquake

\begin{tabular}{lllllll}
\hline No. & $\begin{array}{l}\text { Strong motion } \\
\text { peak values }\end{array}$ & A & B & $\begin{array}{l}\text { Correlation } \\
\text { coefficient }\end{array}$ & $\begin{array}{l}\text { Standard } \\
\text { deviation }\end{array}$ & Readings \\
\hline 1 & $0.3 \mathrm{~s} \mathrm{Sa}$ & 4.90 & -12.07 & 0.95 & 0.48 & 11 \\
2 & $0.3 \mathrm{~s} \mathrm{~Sv}$ & 5.00 & -5.00 & 0.96 & 0.51 & 12 \\
3 & $1 \mathrm{~s} \mathrm{Sa}$ & 5.46 & -12.73 & 0.98 & 0.38 & 13 \\
4 & $1 \mathrm{~s} \mathrm{~Sv}$ & 4.98 & -6.88 & 0.95 & 0.53 & 13 \\
5 & $3 \mathrm{~s} \mathrm{Sa}$ & 5.13 & -10.96 & 0.94 & 0.54 & 12 \\
6 & $3 \mathrm{~s} \mathrm{~Sv}$ & 5.20 & -8.30 & 0.96 & 0.49 & 13 \\
7 & Averaged Sa & 5.40 & -12.59 & 0.97 & 0.43 & 12 \\
8 & Averaged Sv & 5.25 & -7.26 & 0.96 & 0.46 & 13 \\
9 & PGA & 4.61 & -11.19 & 0.97 & 0.38 & 12 \\
10 & PGV & 4.89 & -8.73 & 0.95 & 0.6 & 14 \\
11 & Seismic wave & 2.67 & -11.05 & 0.97 & 0.41 & 13 \\
& intensity & & & & & \\
\hline
\end{tabular}

Table II. Regression analysis parameters between fatality rate and strong motion peak values during the 1999 Chi-Chi earthquake

\begin{tabular}{lllllll}
\hline No. & $\begin{array}{l}\text { Strong motion } \\
\text { peak values }\end{array}$ & A & B & $\begin{array}{l}\text { Correlation } \\
\text { coefficient }\end{array}$ & $\begin{array}{l}\text { Standard } \\
\text { deviation }\end{array}$ & Readings \\
\hline 1 & $0.3 \mathrm{~s} \mathrm{Sa}$ & 4.31 & -12.61 & 0.90 & 0.65 & 11 \\
2 & $0.3 \mathrm{~s} \mathrm{~Sv}$ & 3.75 & -5.73 & 0.87 & 0.67 & 11 \\
3 & $1 \mathrm{~s} \mathrm{Sa}$ & 4.56 & -12.68 & 0.92 & 0.58 & 12 \\
4 & $1 \mathrm{~s} \mathrm{~Sv}$ & 4.33 & -7.98 & 0.91 & 0.58 & 12 \\
5 & $3 \mathrm{~s} \mathrm{Sa}$ & 4.48 & -11.58 & 0.89 & 0.65 & 11 \\
6 & $3 \mathrm{~s} \mathrm{~Sv}$ & 3.70 & -7.87 & 0.90 & 0.55 & 11 \\
7 & Averaged Sa & 4.54 & -12.65 & 0.91 & 0.61 & 11 \\
8 & Averaged Sv & 4.60 & -8.41 & 0.91 & 0.61 & 12 \\
9 & PGA & 4.03 & -11.83 & 0.92 & 0.54 & 11 \\
10 & PGV & 4.47 & -9.80 & 0.92 & 0.65 & 13 \\
11 & Seismic wave & 2.11 & -10.70 & 0.90 & 0.67 & 12 \\
& intensity & & & & & \\
\hline
\end{tabular}




$$
\log (D)=A \log (S)+B .
$$

Here, $A$ and $B$ are regression coefficients. Correlation coefficients between strong ground motion parameter peak values and earthquake losses are determined and are shown in Tables I and II. On all eleven strong-motion parameters, Table I gives uniformly high correlation coefficients for household collapse rate, with values from 0.94 to 0.98 . Corresponding standard deviations give a wider spread from 0.38 to 0.60 . All eleven calculated parameters give strong correlation with the earthquake losses. Among them, PGA and $1 \mathrm{~s} \mathrm{Sa}$ are slightly better parameters to gauge the household collapse rate for having smaller standard deviations. An example of correlation results between the averaged household collapse rate and the observed $1 \mathrm{~s} \mathrm{Sa}$ (solid line) is shown in Figure 4. Table II gives for the fatality rate reasonably high correlation coefficients, with values from 0.87 to 0.92 , and standard deviation 0.55 to 0.67 . Generally, these strong-motion parameters correlate better with household collapse rate than with fatality rate, as the former gives higher correlation coefficients with relatively lower standard deviation values. Figure 5 is a plot of Tables I and II, where a solid circle gives the household collapse rate and a solid triangle gives the fatality rate. Comparing all regression results for strong motion peak parameter values, $1 \mathrm{~s} \mathrm{Sa}$, PGA and SWI are three parameters that better correlate with the earthquake loss. $1 \mathrm{~s}$ Sa gives higher correlation coefficient for both household collapse rate and fatality rate. The PGA gives lower standard deviation values for both household collapsed rate and fatality rate. The SWI data offer reasonably good fit in the household collapsed rate. The PGV also gives a high value of the correlation coefficient for the fatality rate. Comparing regression results on the basis of different response spectral amplitudes, $1 \mathrm{~s}$ period signals gives better correlation with earthquake losses than others during the ChiChi earthquake. This is probably the result of the actual collapsed buildings that involve a large number of mid-rise structures 8 to 12 stories in height which have an approximately 1 -s nature period.

The CWB has in the past derived an empirical yet quantitative intensity scale $I_{t}$ for Taiwan based on instrumental PGA values recorded over the past several decades (Wu et al., 2003). Table III gives the definition of It scale for Taiwan and its corresponding values for the Modified Mercalli intensity scale (MMI). In Taiwan, the instrumental intensity scale can be described by:

$$
I_{t}=2.00 \log _{10}(\mathrm{PGA})+0.70 .
$$

Here PGA has a unit in gal, $I_{t}$ is the PGA-based intensity, rounding off to nearest integer. For PGA > 400 gal, it is defined to be intensity 7. Relationship between intensity and PGV was also determined in our previous study (Wu et al., 2003) which gives:

$$
I_{t}=2.14 \log _{10}(\mathrm{PGV})+1.89 .
$$




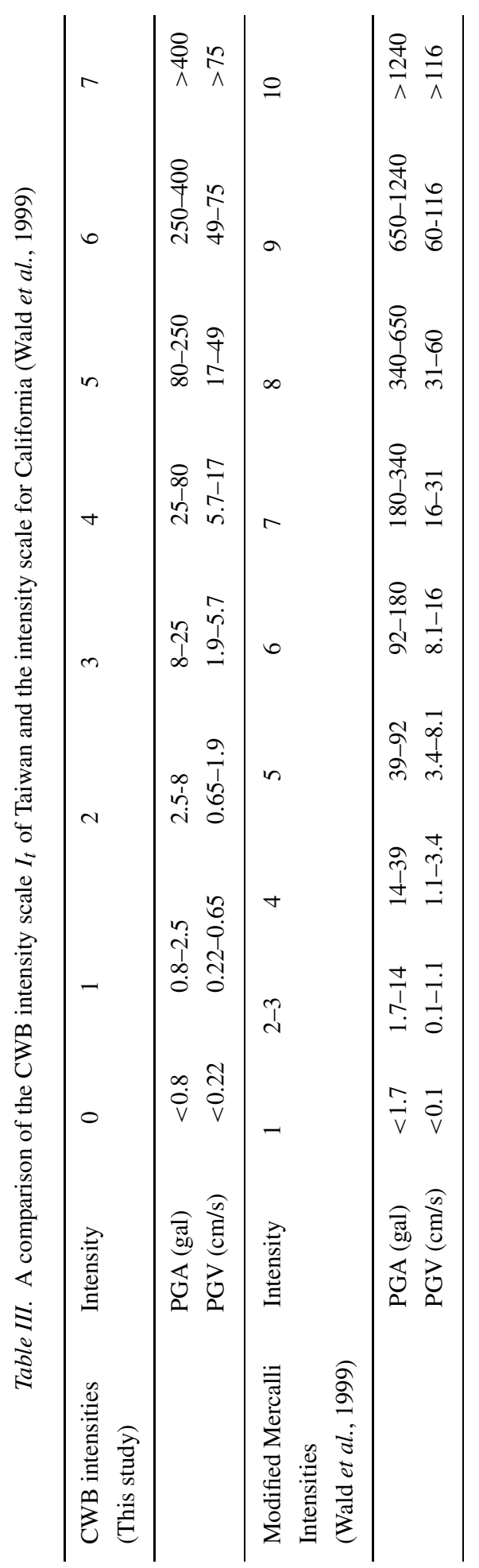




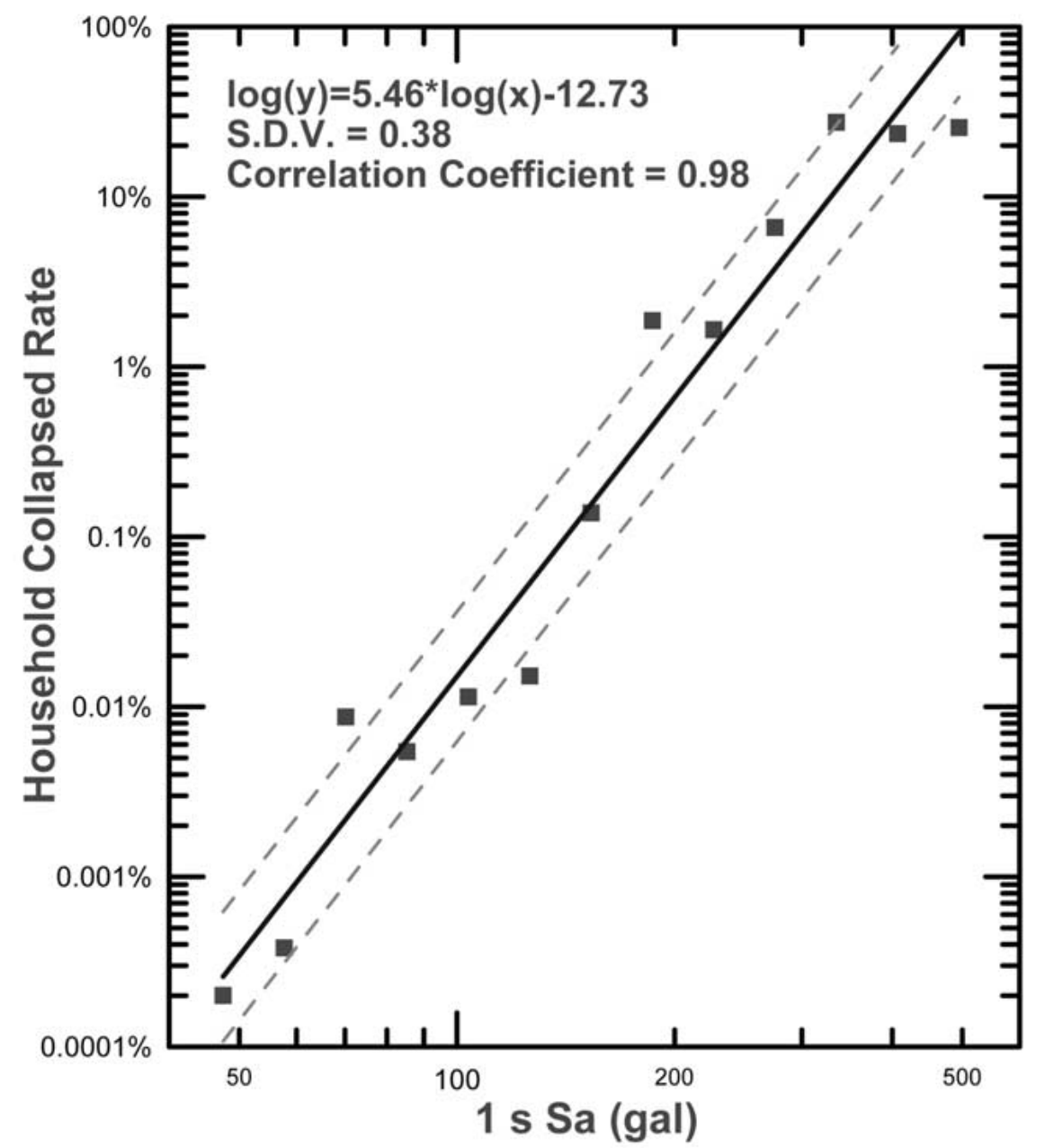

Figure 4. A sample regression result between household collapse rate and $1 \mathrm{~s} \mathrm{Sa} \mathrm{(gal)} \mathrm{values.}$ A high correlation coefficient and a low standard deviation value show reasonably good fit.

Here PGV in $\mathrm{cm} / \mathrm{s}, I_{t}$ is the PGV-based intensity, rounding off to the nearest integer. We also define that for PGV $>75 \mathrm{~cm} / \mathrm{s}, I_{t}=7$. Based on the same data set on household collapse rate during the 1999 Chi-Chi earthquake, applying Equation (1) and parameters in Table II we can derive the relationships between, respectively, SWI, 1 s Sa and PGA as follows:

$$
\begin{aligned}
& \log _{10}(\mathrm{PGA})=0.58 \log _{10}(S W I)+0.03, \\
& \log _{10}(P G A)=1.18 \log _{10}(1 \mathrm{~s} \mathrm{Sa})-0.33 .
\end{aligned}
$$



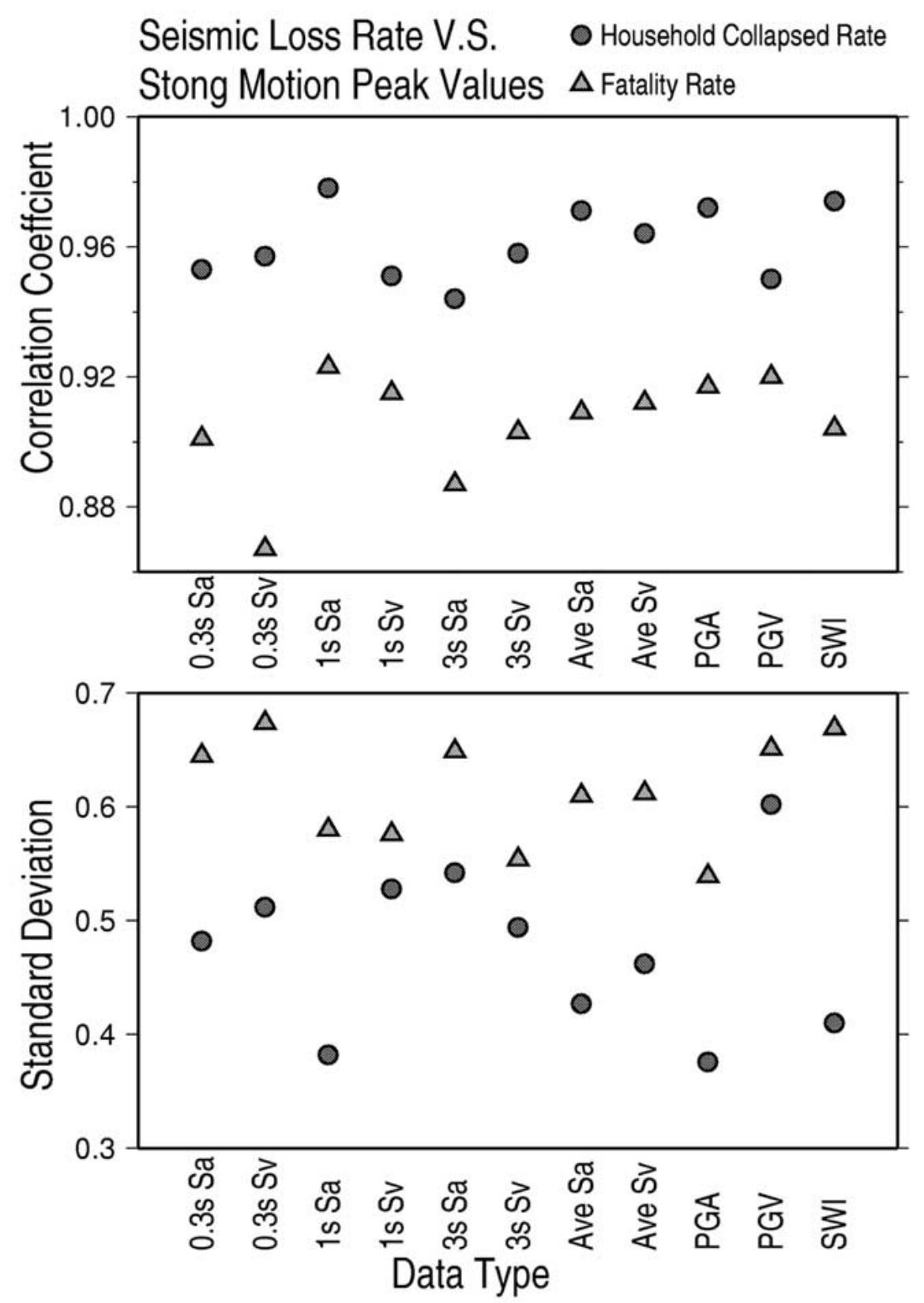

Figure 5. Plots of regression results for all 11 strong-motion parameters (along horizontal axis) and the corresponding correlation coefficients (top panel) and standard deviation values (bottom panel). Solid circles give the household collapse rates, solid triangles give the fatality rates. 
Substituting Equations (4) into Equation (1), we have relationships between, respectively, SWI, $1 \mathrm{~s}$ Sa and the intensity It as follows:

$$
\begin{aligned}
& I_{t}=1.16 \log _{10}(\mathrm{SWI})+0.76, \\
& I_{t}=2.36 \log _{10}(1 \mathrm{~s} \mathrm{Sa})+0.04 .
\end{aligned}
$$

\section{Discussions}

According to the above regression analysis results, PGA and $1 \mathrm{~s} \mathrm{Sa}$ are two parameters that which correlate better with seismic damage during the Chi-Chi earthquake. However, PGA values alone are not particularly reliable in damage assessment; this is particularly true for smaller $(M<5)$ earthquakes. For example, smaller earthquakes $(M<5)$ are generally not damaging in Taiwan. Their induced strong motions in close-in distances can sometimes give sharp high PGA spikes. With dense instrument deployments of TSMIP, it gives strong-motion recordings of high spatial resolution which can be used to analyze the spatial variations of these high PGA spikes from small events. It is commonly noted that these large PGA values for small events occur in small local neighborhoods and the PGA peaks disappear quickly when even slightly (sometimes less than $1 \mathrm{~km}$ ) removed from these locations. These spikes are generally non-damaging but nonetheless will cause earthquake damage over-estimation. Figure 6 shows an $M_{L}=3.7$ event that has developed an excessively high PGA of 549 gal, while the corresponding PGV is only a normal $6.6 \mathrm{~cm} / \mathrm{s}$. Clearly, these sharp PGA spikes are usually characterized by a single peak rich in high frequencies and short in shaking durations. Generally, small earthquakes cannot give rise to high PGV values. Thus, in our previous study (Wu et al. 2002, 2003) we recommend the use of PGV instead PGA for instrumental intensity calculations, which help to remove the above excessively high PGA irregularities.

We have assembled a set of 2,043 TSMIP measurements with PGA values larger than 80 gal from 1993 to 2001. In Figure 7, all 2043 PGA values and the corresponding calculated PGV, SWI and $1 \mathrm{~s}$ Sa values are plotted against local magnitude $M_{L}$. Also plotted alongside on the left is the intensity scale determined from Equation (2), as well as on the right the corresponding MMI intensity scale. From this large data set, we find that the PGA values do not have resolution to distinguish large from small events. Indeed, in the example shown in the top panel of Figure 7, events as small as $M_{L} \sim 3.7$ can generate PGA $>500$ gal that would correspond to a Taiwan CWB instrumental intensity 7 (or MMI IX). Figure 7A shows just that where high PGA values are seen from events $M_{L} 3.7$ and up. However, in Figure 7B, 7C, and 7D, the maximum PGV, 1 s Sa and SWI values are more discriminative. Their peak values are more proportional to $M_{L}$ and give rise to a more reasonable intensity levels. This is especially true for PGV and $1 \mathrm{~s}$ Sa values. In Taiwan, a $M_{L}<6$ earthquake almost never cause damage, thus the 
1997/06/14 19:59:32, Lat. 24.44, Long.121.74, Depth=8.0, $M_{L}=3.7$

ILA065, Epi-distance $=4.4 \mathrm{~km}$, E-W Component
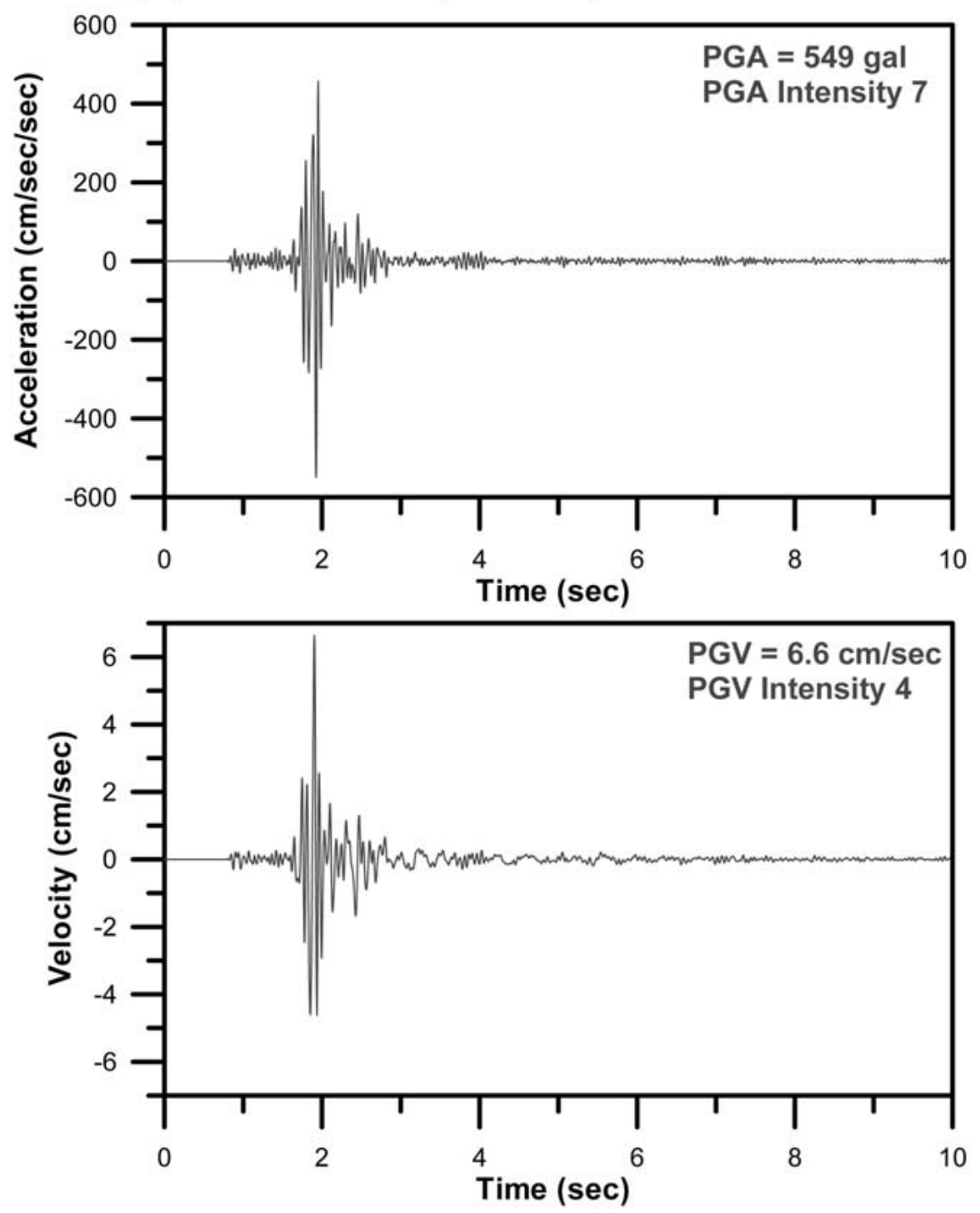

Figure 6. Seismograms showing the occasional development of high PGA values (top panel: 549 gal in this example). Corresponding PGV for the same event (bottom panel) only developed $6.6 \mathrm{~cm} / \mathrm{sec}$, a more reasonable value for small event of this size. 

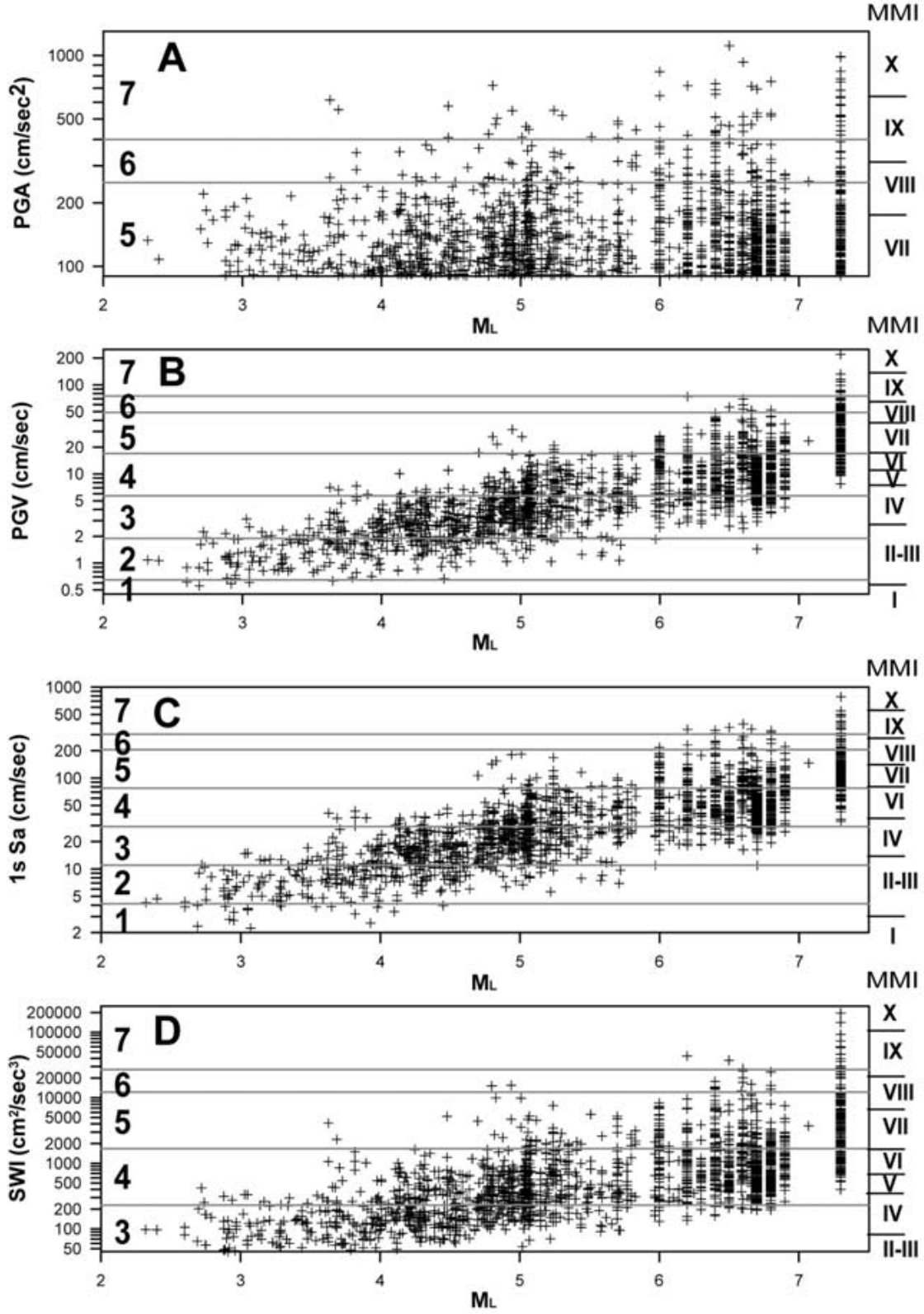

Figure 7. A plot of all 2043 data points versus ML. On the left is the Taiwan CWB instrumental intensity scale given in Arabic numerals, on the right is the instrumental MMI scale given in Roman numerals. Four strong-motion parameters are plotted in panels from the top: A. PGA; B. PGV; C. $1 \mathrm{~s} \mathrm{Sa}$; D. SWI (refer to the text for definitions). 
corresponding maximum CWB intensity should be less than 5 . In fact, the currently CWB intensity 5 (or MMI > VII) implies light damage. PGV and $1 \mathrm{~s} \mathrm{Sa}$ are two parameters that are consistent with this intensity definition. During the time period of the strong-motion data used here, only the Chi-Chi earthquake has caused heavy damages, it means that $M_{L}<7$ earthquakes cannot produce a CWB intensity 7 (or MMI IX). PGV and SWI are two parameters conform with this definition. PGV is a good parameter that fits both of these two conditions. However, for events much smaller than $M_{L} \sim 5, \mathrm{PGV}$ and $1 \mathrm{~s}$ Sa values tend to underestimate the intensity by about one intensity unit especially when values of PGA $>80$ gal are widespread. SWI values also give a more reasonable intensity values for small magnitude earthquakes.

\section{Conclusions}

In this study, we investigated the relationships between earthquake loss and strong motion peak values, mainly based on the excellent loss statistics from the Chi-Chi earthquake. Since both the strong-motion peak values and the earthquake loss are clearly causally related, their correlation is expected to be high. Tables I and II summarize regression relations derived from the analysis. The regression results indeed show that, and all eleven parameters provide adequate earthquake damage and life loss pre-assessments. These relations provide a quantitative means by which predictions of strong ground motion and earthquake damage can be incorporated into the real-time seismic monitoring software for future earthquake rapid reporting and early warning operations. Real-time strong ground motion prediction and damage pre-assessment would be an important step towards hazard mitigation in post-earthquake emergency responses. From the results, we found that PGA and $1 \mathrm{~s} \mathrm{Sa}$ values are two parameters that give slightly higher correlation coefficients than other parameters. Figure 7 also summarizes large data sets of PGA, PGV, $1 \mathrm{~s}$ $\mathrm{Sa}$ and SWI over broad magnitude and intensity ranges. We found that the PGV values, and to some extend the $1 \mathrm{~s}$ Sa values, are better parameters for intensity estimations in the high range. But PGV and $1 \mathrm{~s}$ Sa values tend to under-estimate the intensity in low magnitude events. On the other hand, SWI values give a more reasonable intensity estimation for small magnitude events. Although PGV values give a slightly lower correlation coefficient ( 0.95 compared to the highest value of 0.98 ) and larger standard deviation (0.6 compared to the lowest value of 0.38 ), it nevertheless give more reliable instrumental intensity over a broad magnitude range. $1 \mathrm{~s} \mathrm{Sa}$ is a good parameter for both seismic losses and intensity evaluation. We thus conclude that PGV and $1 \mathrm{~s}$ Sa are relatively more stable in damage assessment and, at least in the high end, in intensity estimation. PGA is not stable for intensity estimation especially for smaller earthquakes. We shall incorporate these findings in our real-time earthquake rapid reporting and early warning algorithms. 


\section{Acknowledgments}

The authors are deeply grateful to Profs. Yi-Ben Tsai, Willie Lee, Tzay-Chyn Shin, Tom Beer and two anonymous reviewers for their valuable comments. This study was supported by the Central Weather Bureau and the National Science Council of the Republic of China under Grant No. NSC91-2116-M-052-001.

\section{References}

Cressie, N. A. C.: 1990, The origins of Kriging, Mathematical Geology 22, 239-252.

Kanamori, H., Hauksson, E., and Heaton, T.: 1997, Real-time seismology and earthquake hazard mitigation, Nature 390, 461-464.

Kanamori, H., Maechling, P., and Hauksson, E.: 1999, Continuous monitoring of ground-motion parameters, Bull. Seism. Soc. Am. 89, 311-316.

Lee, W. H. K., Shin, T. C., Kuo, K. W., Chen, K. C., and Wu, C. F.: 2001, CWB free-field strongmotion data from the 21 September Chi-Chi, Taiwan, earthquake, Bull. Seism. Soc. Am. 91, 13701376.

National Office of Statistics: 2000, Summary of important population statistics in 1999 (in Chinese), 921 Earthquake Post-Disaster Recovery Commission, http:/www.921erc.gov.tw.

National Office of Statistics: 2001, Important statistics about the Chi-Chi earthquake disaster (in Chinese), 921 Earthquake Post-Disaster Recovery Commission, http:/www.921erc.gov.tw.

Ouchi, T., Lin, A., Chen, A., and Maruyama, T.: 2001, The 1999 Chi-Chi (Taiwan) Earthquake: earthquake fault and strong motions, Bull. Seism. Soc. Am. 91, 996-976.

Teng, T. L., Wu, L., Shin, T. C., Tsai, Y. B., and Lee, W. H. K.: 1997, One minute after: strong-motion map, effective epicenter, and effective magnitude, Bull. Seism. Soc. Am. 87, 1209-1219.

Tsai, Y. B., Yu, T. M., Chao, H. L., and Lee, C. P.: 2001, Spatial distribution and age dependence of human-fatality rates from the Chi-Chi, Taiwan, Earthquake of 21 September 1999, Bull. Seism. Soc. Am. 91, 1298-1309.

Wald, D. J., Quitoriano, V., Heaton, T. H., and Kanamori, H.: 1999, Relationships between peak ground acceleration, peak ground velocity and Modified Mercalli Intensity in California, Earthquake Spectra 15, 557-564.

Wu, Y. M., Chen, C. C., Shin, T. C., Tsai, Y. B., Lee, W. H. K., and Teng, T. L.: 1997, Taiwan Rapid Earthquake Information Release System, Seism. Res. Lett. 68, 931-943.

Wu, Y. M., Shin, T. C., and Tsai, Y. B.: 1998, Quick and reliable determination of magnitude for seismic early warning, Bull. Seism. Soc. Am. 88, 1254-1259.

Wu, Y. M., Chung, J. K., Shin, T. C., Hsiao, N. C., Tsai, Y. B., Lee, W. H. K., and Teng, T. L.: 1999, Development of an integrated seismic early warning system in Taiwan - case for the Hualien area earthquakes, TAO 10, 719-736.

Wu, Y. M., Lee, W. H. K., Chen, C. C., Shin, T. C., Teng, T. L., and Tsai, Y. B.: 2000, Performance of the Taiwan Rapid Earthquake Information Release System (RTD) during the 1999 Chi-Chi (Taiwan) earthquake, Seismo. Res. Lett. 71, 338-343.

Wu, Y. M., Shin, T. C., and Chang, C. H.: 2001, Near real-time mapping of peak ground acceleration and peak ground velocity following a strong earthquake, Bull. Seism. Soc. Am. 91, 1218-1228.

Wu, Y. M., Hsiao, N. C., Teng, T. L., and Shin, T. C.: 2002, Near real-time seismic damage assessment of the rapid reporting system, TAO 13, 313-324.

Wu, Y. M., Teng, T. L., Shin, T. C., and Hsiao, N. C.: 2003, Relationship between peak ground acceleration, peak ground velocity, and intensity in Taiwan, Bull. Seism. Soc. Am. 93, 386-396.

Wu, Y. M. and Teng, T. L.: 2002, A virtual subnetwork approach to earthquake early warning, Bull. Seism. Soc. Am. 92, 2008-2018. 
